Network Compatibility, Intensity of Competition and Process R\&D : A Generalization

Sumit Shrivastav

Indira Gandhi Institute of Development Research, Mumbai February 2020 


\title{
Network Compatibility, Intensity of Competition and Process R\&D : A Generalization
}

\author{
Sumit Shrivastav \\ Email(corresponding author): shrivastav@igidr.ac.in
}

\begin{abstract}
This paper analyses implications of network compatibility and competition on process innovation in differentiated network goods duopoly. It shows that firms R\&D investments are strategic substitutes (complements), if effective network compatibility is less (more) than product substitutability, regardless of the nature of competition. If $R \& D$ investments are strategic complements, firms always invest in process innovation and they invest more under Bertrand competition than under Cournot competition. If $R \& D$ investments are strategic substitutes, unlike Cournot firms, Bertrand firms don't always undertake process innovation; but, when Bertrand firms also undertake process innovation, Cournot-Bertrand $R \& D$ ranking depends on the strength of network externalities.
\end{abstract}

Keywords: Network compatibility, Network Externalities, Process R\&D, Bertrand-Cournot Compari- son, Product Differentiation

JEL Code: L13, D43, O31 


\title{
Network Compatibility, Intensity of Competition and Process R\&D : A Generalization
}

\author{
Sumit Shrivastav \\ Indira Gandhi Institute of Development Research (IGIDR) \\ Film City Road, Santosh Nagar, Goregaon (E) - Mumbai, 400065, India. \\ Email: shrivastav@igidr.ac.in
}

\begin{abstract}
This paper analyses implications of network compatibility and competition on process innovation in differentiated network goods duopoly. It shows that firms R\&D investments are strategic substitutes (complements), if effective network compatibility is less (more) than product substitutability, regardless of the nature of competition. If R\&D investments are strategic complements, firms always invest in process innovation and they invest more under Bertrand competition than under Cournot competition. If $\mathrm{R} \& \mathrm{D}$ investments are strategic substitutes, unlike Cournot firms, Bertrand firms don't always undertake process innovation; but, when Bertrand firms also undertake process innovation, Cournot-Bertrand $R \& D$ ranking depends on the strength of network externalities.

JEL Codes
\end{abstract}

L13, D43, O31

Keywords

Network compatibility, Network Externalities, Process R\&D, Bertrand-Cournot Comparison, Product Differentiation

Corresponding Address: Indira Gandhi Institute of Development Research (IGIDR), Film City Road, Santosh Nagar, Goregaon (East), Mumbai 400065, India. E-mail: shrivastav@igidr.ac.in. Telephone: +91-9326681338 


\section{Introduction}

This paper attempts to analyze firms' incentives to invest in cost reducing R\&D in differentiated network goods duopoly, where identical competing firms non-cooperatively choose their respective $\mathrm{R} \& \mathrm{D}$ investment levels before they engage in product market competition. The framework considered in this analysis (a) distinguishes between degree of product differentiation and the extent of network compatibility and (b) allows to examine the implications of imperfect compatibility of any order between the two networks (one network of each firm's consumers), and, thus, encompasses perfect network compatibility and perfect network incompatibility as two special cases. It compares and contrasts equilibrium outcomes under Bertrand competition with that under Cournot competition in the product market in order to understand the implications of product market competition on firms' optimal R\&D behavior in alternative scenarios.

It first demonstrates that the strategic nature of competing firms' $R \& D$ investments crucially depends on relative magnitudes of effective network compatibility and product differentiation measures. Each firm perceives that its own R\&D investment and its rival's R\&D investments are strategic substitutes (strategic complements), if effective network compatibility is smaller (larger) than the extent of product substitutability. This is true regardless of whether there is Cournot competition or Bertrand competition in the product market. The reason is, investment in $\mathrm{R} \& \mathrm{D}$ by a firm reduces its own marginal cost of production, which enables that firm to behave more aggressively, i.e. to expand output or undercut price depending on the mode of competition, in the product market. In the case of smaller (larger) effective network compatibility compared to the extent of product substitutability, the direct negative effect of rival firms' aggressive behavior on a firm's market demand dominates (is dominated by) the corresponding indirect positive effect due to increase in that firm's effective network size and, thus, a firm's marginal gain from investing in R\&D decreases (increases) due to increase in its rivals' R\&D investment. Clearly, in absence of network externalities, as in the case of standard non-network goods oligopolies, the condition for competing firms' cost reducing R\&D investments to be strategic substitutes is 
always satisfied, ceteris paribus. ${ }^{1}$ It is well argued that the strategic nature of competing firms' choice variables is likely to have significant bearings to the equilibrium outcomes (see, e.g. Bulow et al., 1985). However, to the best of our knowledge, existing studies on process innovation in network goods oligopoly implicitly assume that competing firms' R\&D investments are strategic substitutes. This paper offers a more general analysis that allows for R\&D investments to be strategic complements as well.

Next, it shows that in the equilibrium Cournot firms always undertake process innovation, regardless of whether $R \& D$ investments are strategic substitutes or strategic complements. In contrast, if R\&D investments are strategic substitutes, Bertrand firms does not undertake process innovation in the equilibrium unless the two networks are sufficiently compatible to each other. It also demonstrates that (i) when R\&D investments are strategic complements, Bertrand competition results in higher R\&D investment by each firm in the equilibrium compared to that under Cournot competition and (b) when R\&D investments are strategic substitutes and firms undertake process innovation regardless of the nature of product market competition, each firm invests more (less) in R\&D in the equilibrium under Bertrand competition than under Cournot competition provided that the strength of network externalities is (not) sufficiently high, given the extent of network compatibility and degree of product differentiation. These are new results.

A number of studies have attempted to compare equilibrium investments in cost reducing process R\&D under Cournot and Bertrand competition. Considering non-network goods oligopoly, Qiu (1997) and Lin and Saggi (2002) demonstrate that a Cournot firm always

\footnotetext{
${ }^{1}$ Note that R\&D investments can be strategic complements even in case of standard non-network goods oligopoly, provided that there is sufficiently high R\&D spillover (Chalioti, 2019; Amir and Knauff, 2008). However, the mechanism driving the result of $R \& D$ complementarity in the present paper differs from that in models of R\&D spillover in non-network goods industries. In order to alienate the implications of network compatibility on firm's R\&D behavior and for the sake of simplicity this paper sidesteps the issue of R\&D spillover. Nonetheless, intuitively it can be said that presence of strong R\&D spillover in the present context is likely to enhance the possibility of having strategic complementarity of R\&D.
} 
invests more in process R\&D than a Bertrand firm does. ${ }^{2}$ The reason behind this result is as follows. Investment in cost reducing innovation by a non-network goods producing firm has two-fold effect on its profit: (i) the direct positive effect, due to reduction in its marginal cost of production, and (ii) the strategic effect, which is the indirect effect of a firm's R\&D investment on its profit via the effect of its $R \& D$ investment on its rival's strategic variable, quantity or price, for product market competition. A firm's marginal cost reduction, due to an increase in its $R \& D$ investment, induces contraction in its rival's output (price) under Cournot (Bertrand) competition and that, in turn, enhances (reduces) its profit. As a result, under Cournot (Bertrand) competition the strategic effect of R\&D investment is positive (negative), which further reinforces (works against) the positive direct effect, in non-network goods oligopoly. In network goods oligopoly, however, the strategic effect works not only through rival's strategic variable for product market competition, but also through strategic interaction between a firm's own and rival firm's strategic variable and consumers' expectations regarding network size. Note that in the presence of network externalities, firms' effective market demands are endogenous. If a firm produces more output or sets lower price, consumers' expectations regarding that firm's network size increases, which in turn has a positive effect on the equilibrium profit of that firm. When R\&D investment levels are strategic complements, this strategic effect via consumers' expectations is sufficiently large to overcompensate the negative strategic effect via rival's strategic variable under Bertrand competition. This induces Bertrand firms to invest more in process R\&D than Cournot firms. However, in case of strategic substitutes, for a Bertrand firm to invest more in R\&D than a Cournot firm, overcompensation by this strategic effect via consumers' expectations depends on the critical strength of network

\footnotetext{
${ }^{2}$ While Qiu (1997) and Lin and Saggi (2002) consider horizontal product differentiation, the CournotBertrand R\&D ranking remains the same in case products are vertically differentiated (see Bonnano and Haworth, 1998). These studies consider that the extent of reduction in marginal cost of production is increasing in $R \& D$ investment, as considered in the present paper. In alternative scenarios, in which the extent of marginal cost reduction is exogenously given, non-network goods producing Bertrand firms may invest more in R\&D than their Cournot counterparts (Bester and Petrakis, 1993; Pal, 2010).
} 
externalities.

There is a vast and growing literature on innovation by oligopolistic firms in the presence of network externalities. Following Farrell and Saloner $(1985,1986)$ and Katz and Shapiro $(1985,1986)$ several authors have analyzed the relation between network externalities and firms' incentives for product innovation in oligopolies. ${ }^{3}$ However, the issue of process innovation in the presence of network externalities has received rather limited attention in the literature so far. To the best of our knowledge, Boivin and Vencatachellum (2002), Saaskilahti (2006) and Naskar and Pal (2020) are the only exceptions in this regard. Considering that networks are perfectly compatible, Boivin and Vencatachellum (2002) examine the impact of network externalities on process $R \& D$ in a homogeneous network goods Cournot duopoly. They argue that in the presence of network externalities firms invest at least as much in process R\&D as in the absence of network externalities. ${ }^{4}$ Saaskilahti (2006) allow for R\&D spillover and imperfect network compatibility, but restricts the analysis to the case of price competition in a linear city model. Very recently, Naskar and Pal (2020) offer an analysis of differentiated network goods producing firms incentives to invest in cost reducing process $\mathrm{R} \& \mathrm{D}$ under alternative modes of product market competition, quantity and price, in two alternative scenarios: (i) perfect incompatibility of networks and (ii) the extent of network compatibility is same as the extent of product substitutability. This paper is closely related to Naskar and Pal (2020). However, unlike Naskar and Pal (2020), this paper considers a wider parameter space that allows for the extent network compatibility to vary from zero (i.e. perfect incompatibility) to one (i.e. perfect comparability). The present analysis encompasses the scenarios considered in Naskar and Pal (2020) as special cases. More importantly, while the scope of Naskar and Pal (2020) is restricted to the case of strategic substitutability of $R \& D$ investments by firms, this paper considers both strategic substitutability and strategic complementarity.

\footnotetext{
${ }^{3}$ See Katz and Shapiro (1992), Kristiansen and Thum (1997), Kristiansen (1996, 1998), Cerquera (2006) and Xing (2014), to name a few.

${ }^{4}$ They also show that the equilibrium may not be unique, when network effect is non-linear. The present paper considers, for simplicity, that consumers' marginal willingness to pay is linearly in network size.
} 
The remaining part of the paper is organized as follows. Section 2 presents the framework of the model. Section 3 and Section 4 analyze the equilibrium R\&D behavior of firms under Bertrand competition and Cournot competition, respectively. Section 5 presents the main result of Cournot-Bertrand R\&D comparison. A discussion on comparison of other equilibrium outcomes is presented in Section 6. Section 7 concludes.

\section{The Model}

Consider that there are two firms in the market. Firms produce network goods, which are differentiated. Consumers of a network good derive higher utility, if more consumers consume that good. That is, there are two networks, one for each firm's product. These two networks are either perfectly compatible, or perfectly incompatible, or imperfectly compatible to each other. In case these two networks are compatible to each other, utility of consumers of one good increases due to increase in the number of consumers of the other good as well, while the extent of such an increase depends on the degree of network compatibility and the strength of network externalities.

The utility function of the representative consumer is assumed to be as follows. ${ }^{5}$

$U\left(q_{1}, q_{2} ; y_{1}, y_{2}\right)=\alpha\left(q_{1}+q_{2}\right)-\frac{q_{1}^{2}+q_{2}^{2}+2 \beta q_{1} q_{2}}{2}+n\left[\left(y_{1}+k y_{2}\right) q_{1}+\left(y_{2}+k y_{1}\right) q_{2}-\frac{y_{1}^{2}+y_{2}^{2}+2 k y_{1} y_{2}}{2}\right]$,

where $\alpha(>0)$ is a demand parameter, $q_{i}(\geq 0)$ denotes the quantity produced by firm $i$, and $y_{i}(\geq 0)$ denotes the consumer's expectation about firm $i$ 's total sale, $i=1,2$. $\beta=\frac{\partial^{2} U}{\partial q_{1} \partial q_{2}} \in(0,1)$ is the product differentiation parameter. A lower value of $\beta$ indicates

\footnotetext{
${ }^{5}$ This form of the utility function is a generalization of the utility function considered in several studies including Hoernig (2012), Bhattacharjee and Pal (2014), Pal (2014), Pal (2015) and Song and F.S.Wang (2017), to name a few (henceforth 'h-utility function'). The utility function (1) encompasses the h-utility function as special case in which $k=\beta$. The utility function (1) is the same as in Naskar and Pal (2020). However, Naskar and Pal (2020) restrict their analysis by considering two special cases, $k=\beta$ and $k=0$, only.
} 
higher degree of product differentiation. In other words, $\beta$ measures the extent of product substitutability. The parameter $k \in[0,1]$ measures the extent of network compatibility: a higher value of $k$ indicates greater compatibility between the two networks. The two extreme values $k=0$ and $k=1$ corresponds to perfect incompatibility and perfect compatibility, respectively, between the two networks. Thus, the effective network size of firm $i$ is given by $s_{i}=y_{i}+k y_{j} ; i, j=1,2, i \neq j$. The parameter $n=\frac{\partial}{\partial s_{i}}\left[\frac{\partial U}{\partial q_{i}}\right]=\frac{\partial}{\partial y_{i}}\left[\frac{\partial U}{\partial q_{i}}\right] \in[0,1)$, $i=1,2$, measures the strength of network externalities: a higher value of $n$ indicates stronger network externalities, while $n=0$ corresponds to the case of non-network goods. Clearly, $k n=\frac{\partial}{\partial y_{j}}\left[\frac{\partial U}{\partial q_{i}}\right] \in[0,1) ; i, j=1,2, i \neq j$ measures the extent of effective network compatibility in the present context. ${ }^{6}$

The direct market demand function of good $i(=1,2)$ derived from the above utility function is as follows.

$$
q_{i}=\frac{(1-\beta) \alpha-p_{i}+\beta p_{j}+n(1-k \beta) y_{i}+n(k-\beta) y_{j}}{1-\beta^{2}} ; i, j=1,2, i \neq j .
$$

Corresponding inverse market demand function of firm $i$ can be written as

$$
p_{i}=\alpha-q_{i}-\beta q_{j}+n\left(y_{i}+k y_{j}\right) ; i, j=1,2, i \neq j \text {. }
$$

Clearly, the larger the effective network size $s_{i}=y_{i}+k y_{j}$ of firm $i$, higher is the consumers' willingness to pay for good $i$ for any given quantities $q_{i}$ and $q_{j}$.

Initially, each firm has the same constant marginal cost of production $c,(0<c<\alpha)$. However, firm $i(=1,2)$ can reduce its marginal cost of production from $c$ to $\left(c-x_{i}\right)$ by investing $x_{i} \in[0, c]$ in process $\mathrm{R} \& \mathrm{D}$. The cost of firm $i$ 's $\mathrm{R} \& \mathrm{D}$ investment is given by $F_{i}\left(x_{i}\right)=(\lambda / 2)\left(x_{i}\right)^{2}$, where $\lambda(>0)$ is the $\mathrm{R} \& \mathrm{D}$ cost parameter. We assume that marginal cost of $R \& D$ increases at a sufficiently higher rate with the increase in R\&D investment, i.e. $\frac{\partial^{2} F_{i}\left(x_{i}\right)}{\partial x_{i}^{2}}=\lambda$, is sufficiently large, as implied by Assumption 1, which ensures that second

\footnotetext{
${ }^{6}$ Note that $k n=-\frac{\partial}{\partial y_{j}}\left[\frac{\partial U}{\partial y_{i}}\right] ; i, j=1,2, i \neq j$.
} 
order conditions and stability conditions are satisfied in each of the cases considered in this analysis.

Assumption 1: $\lambda>\max \left\{\lambda_{1}, \lambda_{2}\right\}$, where $\lambda_{1}=\frac{2 \alpha\left(1-\beta^{2}\right)\left(2-n-\beta^{2}\right)}{c\left(2-n+k n-\beta-\beta^{2}\right)^{2}[(2-\beta)(1+\beta)-(1+k) n]}$ and $\lambda_{2}=$ $\frac{2 \alpha\left(1-\beta^{2}\right)\left(2-n-\beta^{2}\right)}{c\left(2-n+k n-\beta-\beta^{2}\right)[(2-\beta)(1+\beta)-(1+k) n]^{2}}$.

It is easy to check that $\lambda_{1}>(=) \lambda_{2}$, if $\beta>(=) k n$; Otherwise, $\lambda_{1}<\lambda_{2}$, if $\beta<k n$.

We consider a sequential move game between competing firms, in which $R \& D$ investment levels are decided before the product market competition takes place. Stages of the game are as follows.

Stage 1: Firms choose investment level of R\&D, $x_{i}$ and $x_{j}$, independently and simultaneously. Once $\mathrm{R} \& \mathrm{D}$ decisions are taken, these become common knowledge.

Stage 2: Consumers form expectation about firms' sales and, hence, about network sizes. Subsequently, firms engage themselves in product market competition.

In the product market either Cournot competition or Bertrand competition takes place. The nature of product market competition is considered to be exogenously given and known to all from the very beginning of the game.

We mention here that stages of the sequential move game considered in this analysis are the same as in Naskar and Pal (2020). Note that firms are 'network-size taking' while competing in product market a la Katz and Shapiro (1985) and Amir and Lazzati (2011). ${ }^{7}$

\footnotetext{
${ }^{7}$ That is, firms can not credibly commit to output levels/prices but they credibly commit to R\&D investment levels in stage 1 which consumers use to form expectations about firms' outputs. Alternative
} 
We characterize the sub-game perfect Nash equilibrium (SPNE) of the game by backward induction method. In doing so, following Katz and Shapiro (1985) and Amir and Lazzati (2011), we assume that consumers' expectations are fulfilled in the equilibrium. That is, we impose the additional condition of rational expectations by consumers in stage 2 a la Naskar and Pal (2020).

\section{Bertrand Competition}

First consider that firms engage in Bertrand competition in the product market. Thus, in stage 2 , the problem of firm $i$ can be written as follows.

$$
\max _{p_{i}} \pi_{i}^{B}=p_{i} q_{i}\left(p_{i}, p_{j} ; y_{i}, y_{j}\right)-C_{i}\left(q_{i}\left(p_{i}, p_{j} ; y_{i}, y_{j}\right) ; x_{i}\right) ; i, j=1,2, i \neq j
$$

where $C_{i}\left(q_{i} ; x_{i}\right)=\left(c-x_{i}\right) q_{i}+\frac{\lambda}{2} x_{i}^{2}$ is the total cost of firm $i$ and $q_{i}(\cdot)$ is given by equation (2a). Note that, while choosing $p_{i}$, firm $i$ considers $p_{j}, y_{i}, y_{j}, x_{i}$ and $x_{j}$ as given. Solving this problem we get firm $i$ 's price reaction function as follows.

$$
p_{i}=\frac{1}{2}\left[\alpha(1-\beta)+c+n y_{i}(1-\beta k)+n y_{j}(k-\beta)+\beta p_{j}-x_{i}\right]
$$

It is easy to see that prices $p_{i}$ and $p_{j}$ are strategic complements for all values of $n$. Price reaction function of firm $i$ depends upon $y_{i}$ as well as $y_{j}$. It's worth noting that if consumers' expectation about firm's own output is higher, it shifts the reaction function outward and this shift is positively related with the strength of network effects, $n$, whereas higher consumers' expectation about rival's output shifts the reaction curve outward (inward) if $k>(<) \beta$ and the direction of shift is reinforced by stronger network externalities. Following Katz and Shapiro (1985), we obtain Rational Expectations Nash Equilibrium by scenarios in which (a) firms credibly commit to both R\&D investment levels and output/price decisions and (b) firms can not credibly commit to any of the strategic variables, are beyond the scope of this paper. 
imposing $y_{i}=q_{i}, i=1,2$. The equilibrium prices and quantities in stage 2 are as follows:

$$
\begin{gathered}
p_{i}=\frac{((1-\beta)(2+\beta)-(1-k) n)\left(c(1-n-k n+\beta)+\alpha\left(1-\beta^{2}\right)\right)}{\left(2-n+k n-\beta-\beta^{2}\right)((2-\beta)(1+\beta)-(1+k) n)}+ \\
\frac{\left(n\left(3-n+k^{2} n\right)-2-2 k n \beta+(2-n) \beta^{2}\right) x_{i}+(k n-\beta)\left(1-\beta^{2}\right) x_{j}}{\left(2-n+k n-\beta-\beta^{2}\right)((2-\beta)(1+\beta)-(1+k) n)} \\
q_{i}=\frac{(\alpha-c)((1-k) n-(1-\beta)(2+\beta))+(k n-\beta) x_{j}+\left(2-n-\beta^{2}\right) x_{i}}{\left(2-n+k n-\beta-\beta^{2}\right)((2-\beta)(1+\beta)-(1+k) n)}
\end{gathered}
$$

and similarly for firm $j$. The resulting expressions are well defined for $\forall \beta \in(0,1), k \in[0,1]$ and $n \in[0,1)$. The second order and stability conditions are satisfied.

In stage 1 , firms conduct process $R \& D$ simultaneously and independently to maximize their respective profits. That is, the problem of firm $i$ in stage 1 can be written as $\underset{x_{i} \in[0, c]}{\operatorname{Max}} \pi_{i}^{B}\left(p_{i}\left(x_{i}, x_{j}\right), p_{j}\left(x_{i}, x_{j}\right), x_{i}\right) ; i, j=1,2, i \neq j$. Ignoring the non-negativity constraint, the first order condition of the problem yields the following.

$x_{i}=\frac{2\left(1-\beta^{2}\right)\left(2-n-\beta^{2}\right)\left((\alpha-c)\left(2-n+k n-\beta-\beta^{2}\right)-(k n-\beta) x_{j}\right)}{\left(2-n+k n-\beta-\beta^{2}\right)^{2}((2-\beta)(1+\beta)-(1+k) n)^{2} \lambda-2\left(1-\beta^{2}\right)\left(2-n-\beta^{2}\right)^{2}}, i, j=1,2, i \neq j$.

Lemma 1: If the extent of product substitutability is greater (smaller) than effective network compatibility, under Bertrand competition firms' RED investment levels are strategic substitutes (strategic complements): $\frac{\partial}{\partial x_{j}}\left[\frac{\partial \pi_{i}^{B}(\cdot)}{\partial x_{i}}\right]<(>) 0$, if $\beta>(<) n k ; \forall i, j=1,2, i \neq j$. Proof: See Appendix.

Strategic substitutes and strategic complements above have been defined as in Bulow et al. (1985). Lemma 1 defines a cut-off for effective network compatibility in terms of extent of product substitutability below which $R \& D$ investment levels change from being strategic substitutes to strategic complements. It implies that, under Bertrand competition in the product market, firms' $R \& D$ reaction functions are downward (upward) sloping in the $x_{1} x_{2}$-plane, provided that the extent of product substitutability is greater (smaller) than 
effective network compatibility. The reason is as follows. A firm has greater incentive to reduce its marginal cost of production, if market demand for the product is higher. Now, if the rival firm invests more in $R \& D$, rival firm's marginal cost of production reduces by a larger amount, which enables the rival firm to behave more aggressively (by setting lower price) in the product market. More aggressive play by the rival firm in the product market has two opposing effects on the other firm's demand: (a) a negative effect due to product substitutability and (b) a positive effect through network size due to network compatibility. If the extent of product substitutability is greater (smaller) than the effective network comparability, the negative effect dominates (is dominated by) the positive effect and, thus, a firm's marginal profitability of R\&D reduces (increases) due to an increase in rival firm's R\&D.

Note that, if the two networks are perfectly incompatible to each other $(k=0)$ or the extent of network compatibility is same as that of product substitutability $(k=\beta)$, the condition for firms' $\mathrm{R} \& \mathrm{D}$ investments to be strategic substitutes $(\beta>k n)$ is always satisfied. Existing studies on process R\&D in network goods oligopoly assumes that $k \in\{0, \beta\}$ and, thus, focuses only strategic substitutability of R\&D investments. Considering nonnetwork goods oligopoly Chalioti (2019) and Amir and Knauff (2008) argue that firms' R\&D investments can be strategic complements in case $R \& D$ spillover is sufficiently high. However, the underlying mechanism driving Lemma 1 is very different from that in Chalioti (2019) and Amir and Knauff (2008).

Now, solving firms R\&D investment choice problems in stage 1, we obtain the equilibrium $\mathrm{R} \& \mathrm{D}$ investment levels as follows (where superscript $B *$ denotes the equilibrium under Bertrand competition). 


$$
x^{B *}=\left\{\begin{array}{l}
\frac{2\left(1-\beta^{2}\right)(\alpha-c)\left(2-n-\beta^{2}\right)}{\left(2-n+k n-\beta-\beta^{2}\right)((2-\beta)(1+\beta)-(1+k) n)^{2} \lambda-2\left(1-\beta^{2}\right)\left(2-n-\beta^{2}\right)}, \text { if } 2-n-\beta^{2}>\beta-k n \\
0, \text { otherwise }
\end{array}\right.
$$

It is easy to observe that the condition $2-n-\beta^{2}>\beta-k n$ is satisfied for all $\beta<k n$, since $\beta \in(0,1), n \in[0,1)$ and $k \in[0,1]$. However, if $\beta>k n, 2-n-\beta^{2}>\beta-k n$ may or may not hold true. It implies that, if $\mathrm{R} \& \mathrm{D}$ investments are strategic complements, under Bertrand competition in network goods oligopoly firms' equilibrium R\&D investments are always positive. In contrast, if $R \& D$ investments are strategic substitutes, firms may not invest in R\&D in the equilibrium under Bertrand competition in network goods oligopoly. Further note that, if $n=0,2-n-\beta^{2}>\beta-k n$ holds true for all $\beta \in(0,1)$; i.e. in standard non-network goods oligopoly, under Bertrand competition firms always invest in R\&D.

Proposition 1: In the presence of network externalities, if RED investment levels are strategic complements, a Bertrand firm always invests in process REDD. On the other hand, if RED investment levels are strategic substitutes, there exists a critical value $\bar{k}$ of strength of network externalities for given $n$ and $\beta$ such that a Bertrand firm invests in process $R \& D$ if and only if $k>\bar{k}$, where $\bar{k}=1-\frac{2-\beta-\beta^{2}}{n}<1$.

Proof: See Appendix.

The mechanism behind the above proposition can be understood through the direct and the indirect effects of a change in $x_{i}$ on firm $i$ 's profit.

$$
\frac{d \pi_{i}^{B}}{d x_{i}}=\frac{\partial \pi_{i}^{B}}{\partial x_{i}}+\frac{\partial \pi_{i}^{B}}{\partial p_{j}^{B}} \frac{\partial p_{j}^{B}}{\partial x_{i}}+\left[\frac{\partial \pi_{i}^{B}}{\partial y_{i}}\left(\frac{\partial y_{i}}{\partial p_{i}^{B}} \frac{\partial p_{i}^{B}}{\partial x_{i}}+\frac{\partial y_{i}}{\partial p_{j}^{B}} \frac{\partial p_{j}^{B}}{\partial x_{i}}\right)+\frac{\partial \pi_{i}^{B}}{\partial y_{j}}\left(\frac{\partial y_{j}}{\partial p_{i}^{B}} \frac{\partial p_{i}^{B}}{\partial x_{i}}+\frac{\partial y_{j}}{\partial p_{j}^{B}} \frac{\partial p_{j}^{B}}{\partial x_{i}}\right)\right]
$$

In equation (9), effects of an increase in $x_{i}$ on firm $i$ 's profit have been decomposed in to three components. The first term on the right hand side is the direct effect, which is positive; because, an increase in R\&D investment by a firm reduces its marginal cost and that in turn increases its profit. The second term on the right hand side is the strategic 
effect, which is negative. The reason is (i) a reduction in marginal cost of a firm induces it to set a lower price and that causes its rival firm to lower price too $\left(\frac{\partial p_{j}^{B}}{\partial x_{i}}<0\right)$ and (ii) a reduction in rival's price adversely affects a firms profit $\left(\frac{\partial \pi_{i}^{B}}{\partial p_{j}^{B}}>0\right)$, thus, the effect of $x_{i}$ on $\pi_{i}^{B}$ through its effect on $p_{j}$ is negative. The third term captures second order effect of network externalities, which works through effects of firm's own and its rival firm's prices on consumers' expectations about each firm's output. This second order effect is negative, if $k<1-\frac{1-\beta}{n}=k_{0}$, i.e. if networks are sufficiently incompatible; since in that case the increase of firm $i$ 's effective network size $\left(s_{i}=y_{i}+k y_{j}\right)$ due to an increase in consumers' expectation regarding firm $j$ 's sales $\left(y_{j}\right)$ is sufficiently small. When the second order effect is negative, it together with the negative strategic effect dominates the positive direct effect, if network compatibility is even less, i.e. if $k<\bar{k}\left(<k_{0}\right){ }^{8}$ It follows that, when $\mathrm{R} \& \mathrm{D}$ investments are strategic substitutes $(\beta>k n)$, a Bertrand firm invests in process R\&D only if the two networks are sufficiently compatible to each other, given the strength of network externalities and the extent of product substitutability. Nevertheless, it can be checked that, if in the presence of network externalities Bertrand firm invests in process $\mathrm{R} \& \mathrm{D}$, it invests more than that in the absence of network externalities $(n=0)$.

\section{Cournot Competition}

Now consider that firms engage themselves in Cournot quantity competition in the product market. In such a scenario, firm $i$ 's problem in stage 2 is as follows.

$$
\max _{q_{i} \geq 0} \pi_{i}^{C}=p_{i}\left(q_{i}, q_{j} ; y_{i}, y_{j}\right) q_{i}-C_{i}\left(q_{i}, x_{i}\right) ; i, j=1,2, i \neq j ;
$$

where $C_{i}\left(q_{i}, x_{i}\right)=\left(c-x_{i}\right) q_{i}+\frac{\lambda}{2} x_{i}^{2}$ and $p_{i}(\cdot)$ is given by equation $(2 \mathrm{~b})$. From the expression of $\pi_{i}^{C}$ it is easy to check that $\frac{\partial}{\partial q_{j}}\left[\frac{\partial \pi_{i}^{C}}{\partial q_{i}}\right]<0$, i.e., each firm perceives that $q_{i}$ and $q_{j}$ are strategic substitutes.

$$
{ }^{8} k_{0}-\bar{k}=\frac{1-\beta^{2}}{n}>0 .
$$


Solving the quantity choice problem (10) of firm $i$, we obtain its quantity reaction function, which is given by (11).

$$
q_{i}=\frac{1}{2}\left(\alpha-c-\beta q_{j}+x_{i}+n y_{i}+k n y_{j}\right) ; \quad i, j=1,2, i \neq j
$$

Note that, unless the two networks are perfectly incompatible to each other, both (i) an increase in consumer's expectations regarding firm $i$ 's own sales and (ii) an increase in consumer's expectations regarding rival firm $j$ 's sales shift firm $i$ 's quantity reaction curve outwards: $\frac{\partial q_{i}\left(q_{j} ; y_{i}, y_{j}\right)}{\partial y_{i}}=n / 2>0$ and $\frac{\partial q_{i}\left(q_{j} ; y_{i}, y_{j}\right)}{\partial y_{j}}=n k / 2>0, \forall n \in(0,1)$ and $k \in(0,1]$. Nonetheless, the positive effect of consumers' expectations about a firm's own sales on its quantity choice is larger than the the positive effect of consumers' expectations about its rival firm's sales, unless the two networks are perfectly compatible to each other $(k=1)$. In the later case, these two positive effects are of equal magnitude.

Firms quantity reaction functions (11) along with the Rational Expectations conditions $y_{i}=q_{i}$ (as in Katz and Shapiro (1985)) yields the following stage 2 equilibrium prices and quantities, respectively, under Cournot competition.

$p_{i}=\frac{(\alpha+c(1-n+\beta-k n))(2-n+k n-\beta)+\left(n\left(3-n+k^{2} n\right)-2 k n \beta+\beta^{2}-2\right) x_{i}-(\beta-k n) x_{j}}{(2-(1-k) n-\beta)(2-n+\beta-k n)}$,

and

$$
q_{i}=\frac{(\alpha-c)(2-(1-k) n-\beta)+(2-n) x_{i}-(\beta-k n) x_{j}}{4+\left(1-k^{2}\right) n^{2}-\beta^{2}-n(4-2 k \beta)}, \quad i, j=1,2, i \neq j .
$$

It is easy to check, from equation (13), that (a) $\frac{\partial q_{i}}{\partial x_{i}}>0$, (b) $\frac{\partial q_{i}}{\partial x_{j}}>(<) 0$, if $\beta<(>) k n$, and (c) $\left|\frac{\partial q_{i}}{\partial x_{i}}\right|>\left|\frac{\partial q_{i}}{\partial x_{j}}\right|$.

Now, in stage 1 firms choose R\&D investment levels, simultaneously and independently, to maximize their respective profits. Thus, the problem of firm $i(=1,2)$ is given by $\pi_{i}^{C}\left(x_{i}, x_{j}\right)=p_{i}\left(x_{i}, x_{j}\right) q_{i}\left(x_{i}, x_{j}\right)-C_{i}\left(q_{i}\left(x_{i}, x_{j}\right), x_{i}\right) ; i, j=1,2, i \neq j$. From the first order $x_{i} \in[0, c]$ condition of the problem of firm $i$ we get its $\mathrm{R} \& \mathrm{D}$ reaction function as follows. 


$$
x_{i}=\frac{2(2-n)\left((\alpha-c)(2-(1-k) n-\beta)+(\beta-k n) x_{j}\right)}{(2-(1-k) n-\beta)^{2}(2-n-k n+\beta)^{2} \lambda-2(2-n)^{2}} ; i, j=1,2, i \neq j
$$

Lemma 2: Under Cournot competition in the product market, each firm perceives that its own RED investment and its rival firm's REDD investment are strategic substitutes (strategic complements) in case the extent of product substitutability is greater (smaller) than effective network compatibility: $\frac{\partial}{\partial x_{j}}\left[\frac{\partial \pi_{i}^{C}(\cdot)}{\partial x_{i}}\right]<(>) 0$, if $\beta>(<) n k ; \forall i, j=1,2, i \neq j$. Proof: See Appendix.

Lemma 2 implies that under Cournot competition in the product market each firm's R\&D reaction functions are downward (upward) sloping in the $x_{1} x_{2}$-plane, if $\beta>(<) n k$, as under Bertrand competition (Lemma 1). The intuition is also the same as that under Bertrand competition. The following Proposition is immediate from Lemma 1 and Lemma 2 .

Proposition 2: In network goods duopoly, regardless of the nature of product market competition - Cournot or Bertrand, the strategic nature of firms' investments in process RED depends on relative magnitudes of (i) product substitutability and (ii) effective network compatibility. If the former is greater (smaller) than the later, levels of R\&D investments are strategic substitutes (strategic complements).

From Proposition 2 it follows that, if firms' R\&D strategies are strategic substitutes (strategic complements) under Bertrand competition, these are also strategic substitutes (strategic complements) under Cournot competition; and vice-versa. It can be checked that in the special case, when the extent of product substitutability is equal to the measure of effective network compatibility $(\beta=k n)$, there does not exist any strategic interaction between firms at the $R \& D$ stage (i.e. in stage 1), irrespective of whether there is Cournot competition or Bertrand competition in stage 2. In such a knife-edge scenario, R\&D investment 
by a firm does not directly depend on its rival firm's R\&D investment.

Corollary 1: If $\beta=k n, \frac{\partial}{\partial x_{j}}\left[\frac{\partial \pi_{i}^{g} \cdot(\cdot)}{\partial x_{i}}\right]=0, g \in\{C, B\} ; \forall i, j=1,2, i \neq j$

Proof: See Appendix.

Now, solving firms R\&D reaction functions (14), we obtain the equilibrium R\&D investment level of each firm as follows.

$$
x^{C *}=\frac{2(2-n)(\alpha-c)}{(2-\beta-(1-k) n)(2-n-k n+\beta)^{2} \lambda-2(2-n)},
$$

where the superscript $C$ stands for Cournot competition.

Proposition 3: In the presence of network externalities, Cournot firms always invest in process $R \mathscr{E} D$, regardless of the strategic nature of their RED investments.

Proof: See Appendix.

The underlying mechanism behind Proposition 3 is as follows. In stage 1, firm $i$ chooses $x_{i}$ by taking $x_{j}$ as given and correctly anticipating implications of $\mathrm{R} \& \mathrm{D}$ choices on stage 2 equilibrium outcomes. Note that, for any given $x_{j}$,

$$
\frac{d \pi_{i}^{C}}{d x_{i}}=\frac{\partial \pi_{i}^{C}}{\partial x_{i}}+\frac{\partial \pi_{i}^{C}}{\partial q_{j}^{C}} \frac{\partial q_{j}^{C}}{\partial x_{i}}+\left[\frac{\partial \pi_{i}^{C}}{\partial y_{i}} \frac{\partial y_{i}}{\partial q_{i}^{C}} \frac{\partial q_{i}^{C}}{\partial x_{i}}+\frac{\partial \pi_{i}^{C}}{\partial y_{j}} \frac{\partial y_{j}}{\partial q_{j}^{C}} \frac{\partial q_{j}^{C}}{\partial x_{i}}\right] ; \forall i, j=1,2, i \neq j .
$$

An increase in $x_{i}$ affects firm $i$ 's profit through three channels. First term on the right hand side is the direct effect, which is positive unless $x_{i}$ is sufficiently large. This is because, a reduction in marginal cost of firm $i$ positively affects its gross profit (i.e. profit before deducting cost of R\&D). Second term on the right hand side is the strategic effect which is also positive, since a reduction in marginal cost of firm $i$ reduces the rival's output which in turn has a positive impact on $i$ 's profit. The third term in the square bracket on the right hand side is second order effect due to network externalities which is also positive, the explanation of which is as follows. A reduction in firm $i$ 's marginal cost increases 
its output and, thus, increases consumers' expectations regarding its sales, which has a positive effect on its profit. Hence, the effect of a firm's R\&D on its profit via consumers' expectations regrading its own sales (the first term in square bracket) is positive. On the other hand, a reduction in firm $i$ 's marginal cost decreases rival firm $j$ 's output. In the equilibrium, consumers anticipates it correctly and lowers their expectations regarding firm $j$ 's sales, which adversely affects firm $i$ 's demand and profits. Hence, the effect of a firm's $\mathrm{R} \& \mathrm{D}$ on its profit through consumer's expectation regarding its rivals sales (the second term in square bracket) is negative. However, the second order effect through consumers' expectation regarding a firm's own sales is stronger than that through through consumers' expectation regarding rival firm's sales. Since the direct effect, the strategic effect as well as total second order effect are positive, it is always profitable for a Cournot firm to invest in process $\mathrm{R} \& \mathrm{D}$ in the presence of network externalities.

We mention here that Cournot firms always invests in R\&D in absence of network externalities $(n=0)$ as well. The presence of network externalities enhances Cournot firms incentives to invest in $R \& D$.

\section{Bertrand-Cournot R\&D Comparison}

In this section we compare the equilibrium R\&D investment levels under Bertrand and Cournot competition. In the absence of network externalities, Cournot firms invest more in process R\&D than Bertrand firms (Lin and Saggi, 2002) because strategic effect of a decrease in marginal cost acts against the direct positive effect in case of Bertrand competition, as discussed in previous sections. However, in the presence of network externalities, this result may reverse. We compare the results under two cases, strategic complementarity and strategic substitutability of R\&D investment levels.

Proposition 4 : In network goods duopoly the ranking of equilibrium RED investments 
under Bertrand and Cournot competition is as follows.

(i) When firms' R\&D strategies are strategic complements, each firm invests more in process RED in the equilibrium under Bertrand competition compared to that under Cournot competition: when $\beta<k n, x^{B *}>x^{C *} \forall n \in(0,1)$.

(ii) When R\&D investment levels are strategic substitutes, there exists a critical level $n^{*}(\beta, k) \in(0,1)$ of strength of network externalities such that a Bertrand firm invests more in process RED than a Cournot firm, if the strength of network externalities is greater than the critical level: when $\beta>k n, x^{B *}>x^{C *}$ if $n>n^{*}(\beta, k)$.

Proof: See Appendix.

The intuition behind Proposition 4 is as follows. When product differentiation is large (i.e. $\beta$ is less) so that $\mathrm{R} \& \mathrm{D}$ investment levels are strategic complements, intensity of product market competition is less and thus the magnitude of negative (positive) strategic effect of R\&D under Bertrand (Cournot) competition is less. In turn, Bertrand R\&D investment level is always higher than Cournot R\&D investment level. On the other hand, for R\&D investment levels to be strategic substitutes, $\beta$ must be sufficiently large. A larger $\beta$ increases the intensity of product market competition and that in turn increases the magnitude of negative (positive) strategic effect of R\&D in Bertrand (Cournot) competition. Hence, for Bertrand R\&D to be greater than Cournot R\&D, network effects should be sufficiently large, i.e. $n>n^{*}$ should hold true.

In the knife-edge scenario in which there is no strategic interaction between firms in terms of $\mathrm{R} \& \mathrm{D}$ investment choices (i.e. when $\beta=k n$ ), the equilibrium $\mathrm{R} \& \mathrm{D}$ investment under Bertrand competition is greater than that under Cournot competition. The intuition is similar to that in the case of strategic complementarity of R\&D investments.

Corollary 2: If $\beta=k n, x^{B *}>x^{C *} \forall n \in(0,1)$

Proof: See Appendix. 
Note that, if $k \in\{\beta, 0\}$ as in Naskar and Pal (2020), firms R\&D investments are strategic substitutes. From Proposition 4(ii) it follows that (a) $\left.x^{B *}\right|_{k=\beta}>\left.x^{C *}\right|_{k=\beta}$, if $n>n^{*}(\beta, \beta)$, and (b) $\left.x^{B *}\right|_{k=0}>\left.x^{C *}\right|_{k=0}$, if $n>n^{*}(\beta, 0)$. Clearly, results of Naskar and Pal (2020) emerge in special cases of the present analysis.

\section{Further Comparisons}

Although the focus of this paper is on firms' R\&D investments, a discussion on implications of network compatibility on the equilibrium output and prices under alternative modes of product market competition, Bertrand versus Cournot, seems to deserve some attention.

Corollary 3: Suppose that R\&D investment levels are strategic complements (i.e. $\beta<$ $k n)$. Then, output and profit of each firm in the equilibrium under Bertrand competition are higher than those under Cournot competition. Bertrand equilibrium prices are also higher than Cournot equilibrium prices in the presence of sufficiently strong network externalities $\left(\frac{1+\beta}{1+k}<n<1\right)$.

Proof: See Appendix.

Clearly, in the case of strategic complementarity of firms' R\&D investments, standard Bertrand-Cournot profit ranking is always reversed. The reason is, in the presence of network externalities, the strategic variable for product market competition (quantity or price) affects firms' profits through two channels: (i) the direct effect, which is negative in case of more aggressive play in the product market and (ii) the indirect positive effect via consumers' expectations. The overall effect is always higher for Bertrand firms than Cournot firms, whenever R\&D investments are strategic complements. From Corollary 3, it also follows that Bertrand competition results in higher consumers surplus and social welfare (the sum of consumers surplus and firms profits) than Cournot competition in the case of strategic complementarity of R\&D investments, as in non-network goods oligopoly. 
Corollary 4: Suppose that R\&D investment levels are strategic substitutes (i.e. $\beta>k n$ ) and firms undertake process $\mathrm{R} \& \mathrm{D}$ regardless of the mode of product market competition (i.e. $2-n-\beta^{2}>\beta-k n$ ). Then, the equilibrium output (price) of each firm is higher (lower) under Bertrand competition than that under Cournot competition.

Proof: See Appendix.

From Corollary 4 it follows that, when R\&D investment levels are strategic substitutes and firms have incentive to invest in process $R \& D$, the implication of the mode of product market competition on the equilibrium price and output remains the same as in the case of non-network goods oligopoly. However, it turns out that Bertrand-Cournot profit ranking in the case of strategic substitute $R \& D$ investments is ambiguous. We mention here that Pal (2014) argues that the standard Bertrand-Cournot profit ranking gets reversed in the presence of strong network externalities. However, unlike as in this paper, Pal (2014) considers that $k=\beta$ and firms do not undertake any $\mathrm{R} \& \mathrm{D}$ activities.

\section{Conclusion}

This paper develops a model to examine the implications of the mode of product market competition, Bertrand versus Cournot, and network compatibility on the equilibrium investments in marginal cost reducing process $\mathrm{R} \& \mathrm{D}$ by differentiated network goods producing firms. The framework considered in this paper is fairly general, which allows for a larger parameter space compared to Naskar and Pal (2020). It demonstrates that in network goods duopoly firms' R\&D investments may be strategic substitutes or strategic complements, unlike as in Naskar and Pal (2020). If the extent of product substitutability is less (more) than the degree of effective network compatibility, each competing firm perceives that its own R\&D investment and its rival firm's R\&D investment are strategic complements (substitute), regardless of whether firms engage themselves in Bertrand or Cournot competition in the product market. This is a novel finding. Further, it shows that, while Cournot firms always invest in $R \& D$, Bertrand firms do not always have the 
incentive to invest in $R \& D$ in case firms' $R \& D$ strategies are strategic substitutes. When firms R\&D strategies are strategic complements, Bertrand competition results in higher investment in $\mathrm{R} \& \mathrm{D}$ in the equilibrium Compared to Cournot competition. In contrast, when firms $R \& D$ strategies are strategic substitutes, the equilibrium investment in $R \& D$ under Cournot competition is higher than that under Bertrand competition, unless there is sufficiently strong network externalities. These are new results. This paper, thus, offers new insights to understand the implications of network compatibility and product market competition on firms' optimal investments in process R\&D.

The analysis of this paper considers that market demand functions are linear in expected network size as in Naskar and Pal (2020). While this assumption helps to directly compare results of this paper with that of existing studies and also to keep the analysis fairly simple, it seems to be interesting to allow for non-linear effects of network sizes on demand. We leave this for future research. 


\section{References}

Amir, R. and Knauff, M. (2008). Strategic complementarities and substitutesin R\&D duopoly. Unpublished Manuscript. URL: https://pdfs.semanticscholar.org/51d8/f388a032f5780e17c45dc76f651688c7031a.pdf.

Amir, R. and Lazzati, N. (2011). Network effects, market structure and industry performance. Journal of Economic Theory, 146(6):2389-2419.

Bester, H. and Petrakis, E. (1993). The incentives for cost reduction in a differentiated industry. International Journal of Industrial Organization, 11(4):519-534.

Bhattacharjee, T. and Pal, R. (2014). Network externalities and strategic managerial delegation in Cournot duopoly: Is there a prisoners' dilemma? Review of Network Economics, 12(4):343-353.

Boivin, C. and Vencatachellum, D. (2002). R\&D in markets with network externalities. Economics Bulletin, 12(9):1-8.

Bonnano, G. and Haworth, B. (1998). Intensity of competition and the choice between product and process innovation. International Journal of Industrial Organization, $16: 495-510$.

Bulow, J. I., Geanakoplos, J. D., and Klemperer, P. D. (1985). Multimarket oligopoly: Strategic substitutes and complements. Journal of Political Economy, 93(3):488-511.

Cerquera, D. (2006). Dynamic RESD Incentives with Network Externalities. Discussion Paper No. 06-094. ZEW-Centre for European Economic Research, http://econstor.eu/bitstream/10419/24550/1/dp06094.pdf.

Chalioti, E. (2019). Spillover feedback loops and strategic. Journal of Public Economic Theory, 21(6):1126-1142.

Farrell, J. and Saloner, G. (1985). Standardization, compatibility, and innovation. RAND Journal of Economics, 16(1):70-83. 
Farrell, J. and Saloner, G. (1986). Installed base and compatibility: Innovation, product preannouncements. American Economic Review, 76(1):940-955.

Hoernig, S. (2012). Strategic delegation under price competition and network effects. Economics letters, 117(2):487-489.

Katz, M. and Shapiro, C. (1985). Network externalities, competition and compatibility. American Economic Review, 75(3):424-440.

Katz, M. and Shapiro, C. (1986). Technology adoption in the presence of network externalities. Journal of Political Economy, 94(4):822-841.

Katz, M. and Shapiro, C. (1992). Product introduction with network externalities. Journal of Industrial Economics, 40(1):55-83.

Kristiansen, E. G. (1996). R\&D in markets with network externalities. International Journal of Industrial Organization, 16(6):769-784.

Kristiansen, E. G. (1998). R\&D in the presence of network externalities: Timing and compatibility. RAND Journal of Economics, 29(3):531-547.

Kristiansen, E. G. and Thum, M. (1997). R\&D incentives in compatible networks. Journal of Economics, 65(1):55-78.

Lin, P. and Saggi, K. (2002). Product differentiation, process R\&D, and the nature of market competition. European Economic Review, 46(1):201-211.

Naskar, M. and Pal, R. (2020). Network externalities and process R\&D: A CournotBertrand comparison. Mathematical Social Sciences, 103:51-58.

Pal, R. (2010). Technology adoption in a differentiated duopoly: Cournot versus Bertrand. Research in Economics, 64(2):128-136.

Pal, R. (2014). Price and quantity competition in network goods duopoly: A reversal result. Economics Bulletin, 34(2):1019-1027.

Pal, R. (2015). Cournot vs. Bertrand under relative performance delegation: Implications of 
positive and negative network externalities. Mathematical Social Sciences, 75(May):94101.

Qiu, L. D. (1997). On the dynamic efficiency of Bertrand and Cournot equilibria. Journal of Economic Theory, 75(1):213-229.

Saaskilahti, P. (2006). Strategic R\&D and network compatibility. Economics of Innovation and New Technology, 15(8):711-733.

Song, R. and F.S.Wang, L. (2017). Collusion in a differentiated duopoly with network externalities. Economics Letters, 152:23-26.

Xing, M. (2014). On the optimal choices of R\&D risk in a market with network externalities. Economic Modelling, 38(February):71-74. 


\section{Appendix}

\section{Proof of Lemma 1}

In the case of Bertrand competition,

$$
\frac{\partial}{\partial x_{j}}\left[\frac{\partial \pi_{i}^{B}(\cdot)}{\partial x_{i}}\right]=\frac{2(k n-\beta)\left(1-\beta^{2}\right)\left(2-n-\beta^{2}\right)}{\left(2-n+k n-\beta-\beta^{2}\right)^{2}((1+k) n-(2-\beta)(1+\beta))^{2}}
$$

Since $k, \beta \in(0,1)$ and $n \in[0,1)$,

$1-\beta^{2}>0,2-n-\beta^{2}>0$ and the denominator in the above expression is a squared term, hence positive.

Therefore, $\frac{\partial}{\partial x_{j}}\left[\frac{\partial \pi_{i}^{B}(\cdot)}{\partial x_{i}}\right]\left\{\begin{array}{l}>0, \text { if } \beta<k n \\ <0, \text { if } \beta>k n\end{array}\right.$

That is, $x_{i}$ and $x_{j}$ are strategic complements if $\beta<k n$ and strategic substitutes if $\beta>k n$. $[\mathrm{QED}]$

\section{Proof of Proposition 1}

The equilibrium R\&D investment level of each firm under Bertrand competition is given by equation (8). Note that, $x^{B *}=\frac{2(\alpha-c)\left(1-\beta^{2}\right)\left(2-n-\beta^{2}\right)}{-2\left(1-\beta^{2}\right)\left(2-n-\beta^{2}\right)+\left(2-n+k n-\beta-\beta^{2}\right)((1+k) n-(2-\beta)(1+\beta))^{2} \lambda}>0$, if $2-n-\beta^{2}>\beta-k n$ holds true. Otherwise, if $2-n-\beta^{2} \leqslant \beta-k n, x^{B *}=0$.

Now, note that when $\beta<k n$, the inequality $2-n-\beta^{2}>\beta-k n$ always holds true, for $n \in[0,1), k \in[0,1]$ and $\beta \in(0,1)$. It implies that, when $\mathrm{R} \& \mathrm{D}$ investments are strategic complements, i.e. $\beta<k n, x^{B *}>0$.

Now, when $\beta>k n$, the inequality $2-n-\beta^{2}>\beta-k n$ holds true, provided that $k>1-\frac{2-\beta-\beta^{2}}{n}=\bar{k}$. Alternatively, when $\beta>k n$ and $k \leqslant \bar{k}$, the inequality $2--\beta^{2}>\beta-k n$ does not hold. It follows that, when R\&D investments are strategic substitutes, i.e. when $\beta>k n$, for $x^{B *}>0$ to hold, we must have $k>\bar{k}$. [QED]

\section{Proof of Lemma 2}


In the case of Cournot competition,

$$
\frac{\partial}{\partial x_{j}}\left[\frac{\partial \pi_{i}^{C}(\cdot)}{\partial x_{i}}\right]=\frac{2(2-n)(k n-\beta)}{(2-n-k n+\beta)^{2}(2-n+k n-\beta)^{2}}
$$

Since the denominator is positive and $2-n>0, \frac{\partial}{\partial x_{j}}\left[\frac{\partial \pi_{i}^{C}(\cdot)}{\partial x_{i}}\right]\left\{\begin{array}{l}>0 \text {, if } \beta<k n \\ <0, \text { if } \beta>k n\end{array}\right.$

Therefore, $x_{i}$ and $x_{j}$ are strategic complements if $\beta<k n$ and strategic substitutes if $\beta>k n .[\mathrm{QED}]$

\section{Proof of Proposition 2}

The proof follows directly from Lemma 1 and 2 .

\section{Proof of Corollary 1}

We have the following.

$$
\frac{\partial}{\partial x_{j}}\left[\frac{\partial \pi_{i}^{B}(\cdot)}{\partial x_{i}}\right]=\frac{2(k n-\beta)\left(1-\beta^{2}\right)\left(2-n-\beta^{2}\right)}{\left(2-n+k n-\beta-\beta^{2}\right)^{2}((1+k) n-(2-\beta)(1+\beta))^{2}}
$$

and

$$
\frac{\partial}{\partial x_{j}}\left[\frac{\partial \pi_{i}^{C}(\cdot)}{\partial x_{i}}\right]=\frac{2(2-n)(k n-\beta)}{(2-n-k n+\beta)^{2}(2-n+k n-\beta)^{2}} .
$$

It can be easily seen that both the expressions above are zero when $\beta=k n$.

Hence, if $\beta=k n, \frac{\partial}{\partial x_{j}}\left[\frac{\partial \pi_{i}^{g}(\cdot)}{\partial x_{i}}\right]=0, g \in\{C, B\} ; \forall i, j=1,2, i \neq j$. [QED]

\section{Proof of Proposition 3}

From equation (15), the equilibrium $R \& D$ investment level in Cournot competition is as follows.

$$
x^{C *}=\frac{2(2-n)(\alpha-c)}{(2-\beta-(1-k) n)(2-n-k n+\beta)^{2} \lambda-2(2-n)}
$$

The above expression is positive for all values of $n \in[0,1), k \in[0,1]$ and $\beta \in(0,1)$.

Hence, a Cournot firm always invests in process R\&D. [QED] 


\section{Proof of Proposition 4}

The equilibrium R\&D investments of each firm under Cournot and Bertrand competition are, respectively, given by equations (8) and (15).

Now, first consider that $\beta<k n$. Then, $2-n-\beta^{2}>\beta-k n$ holds true, since $n \in[0,1), \beta \in$ $(0,1)$ and $k \in[0,1]$. It implies that $x^{B *}=\frac{2\left(1-\beta^{2}\right)(\alpha-c)\left(2-n-\beta^{2}\right)}{\left(2-n+k n-\beta-\beta^{2}\right)((2-\beta)(1+\beta)-(1+k) n)^{2} \lambda-2\left(1-\beta^{2}\right)\left(2-n-\beta^{2}\right)}>$ 0 . Comparing this $x^{B *}$ with $x^{C *}$, which is given by equation (15), it is easy to check that $x^{B *}>x^{C *} \forall n \in[0,1)$.

Next, consider that both $\beta>k n$ and $2-n-\beta^{2}>\beta-k n$ hold true. Then $x^{B *}=$ $\frac{2\left(1-\beta^{2}\right)(\alpha-c)\left(2-n-\beta^{2}\right)}{\left(2-n+k n-\beta-\beta^{2}\right)((2-\beta)(1+\beta)-(1+k) n)^{2} \lambda-2\left(1-\beta^{2}\right)\left(2-n-\beta^{2}\right)}(>0)$ and $x^{C *}(>0)$ is given by equation (15). It follows that in this case $x^{B *}>x^{C *}$, if and only if $G<H$, where

$G=\frac{\left(2-n-\beta^{2}-\beta+k n\right)\left(2-n-\beta^{2}+\beta-k n\right)^{2}}{\left(\left(1-\beta^{2}\right)\left(2-n-\beta^{2}\right)\right)}$ and $H=\frac{(2-n-\beta+k n)(2-n+\beta-k n)^{2}}{(2-n)}$.

It can be checked that, for $n>\beta, G<H \forall k, \beta \in(0,1)$. Now, (i) when $n=0, G>H$ and (ii) when $n=\beta, G<H$. Further, $\frac{\partial G}{\partial n}-\frac{\partial H}{\partial n}<0$ for $n \in(0, \beta)$. Hence, for given $k$ and $\beta$, there exists $n^{*}(\beta, k) \in(0, \beta)$, such that for $n>n^{*}(\beta, k), H<G \Longrightarrow x^{B *}>x^{C *}$. Hence, investment level in process R\&D under Bertrand competition will be greater than that under Cournot competition, if $n>n^{*}(\beta, k)$.

Finally, consider that $\beta>k n$, but $2-n-\beta^{2}<\beta-k n$. Then $x^{C *}>0=x^{B *}$, from equations (8) and (15). [QED]

\section{Proof of Corollary 2}

If $\beta=k n$, the inequality $2-n-\beta^{2}>\beta-k n$ holds true. Hence, from equations (8) and (15), we have the following.

$x^{B *}=\frac{2\left(1-\beta^{2}\right)(\alpha-c)\left(2-n-\beta^{2}\right)}{\left(2-n+k n-\beta-\beta^{2}\right)((2-\beta)(1+\beta)-(1+k) n)^{2} \lambda-2\left(1-\beta^{2}\right)\left(2-n-\beta^{2}\right)}>0$ and

$x^{C *}=\frac{2(2-n)(\alpha-c)}{(2-\beta-(1-k) n)(2-n-k n+\beta)^{2} \lambda-2(2-n)}>0, \forall n \in[0,1), \beta \in(0,1)$ and $k \in[0,1]$.

Comparing the above two expressions, it follows that $x^{B *}>x^{C *} \forall n \in[0,1), \beta \in(0,1)$ 
and $k \in[0,1]$ such that $\beta=k n$ is satisfied.

[QED]

\section{Proof of Corollary $3 \& 4$}

(i) When $\beta<k n$,

$$
\begin{gathered}
q^{B *}=\frac{(\alpha-c)((1+k) n+(2-\beta)(1+\beta))((1-\beta)(2+\beta)-(1-k) n) \lambda}{2\left(1-\beta^{2}\right)\left(2-n-\beta^{2}\right)+\left(2-n+k n-\beta-\beta^{2}\right)((2-\beta)(1+\beta)-(1+k) n)^{2} \lambda} \\
q^{C *}=\frac{(\alpha-c)(2-(1-k) n-\beta)(2-n-k n+\beta) \lambda}{(2-(1-k) n-\beta)(2-n-k n+\beta)^{2} \lambda-2(2-n)} \\
p^{C *}=\frac{(\alpha+c(1-n-k n+\beta))(2-(1-k) n-\beta)(2-n-k n+\beta) \lambda-2(2-n) \alpha}{(2(1-k) n-\beta)(2-n-k n+\beta)^{2} \lambda-2(2-n)}
\end{gathered}
$$

Let $L=\frac{2(\alpha-c)(\beta-k n)\left(1-\beta^{2}\right)^{2}\left(2-n-\beta^{2}\right)}{\left(2-n+k n-\beta-\beta^{2}\right)((1+k) n-(2-\beta)(1+\beta))^{2} \lambda-2\left(1-\beta^{2}\right)\left(2-n-\beta^{2}\right)}$,

$M=\frac{2(\alpha-c)\left(1-\beta^{2}\right)\left(2-n-\beta^{2}\right)\left(2-n\left(3-n+k^{2} n\right)+2 k n \beta-(2-n) \beta^{2}\right)}{\left(2-n+k n-\beta-\beta^{2}\right)((1+k) n-(2-\beta)(1+\beta))^{2} \lambda-2\left(1-\beta^{2}\right)\left(2-n-\beta^{2}\right)}$,

$N=((1-k) n-(1-\beta)(2+\beta))\left(c(1-n-k n+\beta)+\alpha\left(1-\beta^{2}\right)\right)$, and

$K=\left(2-n+k n-\beta-\beta^{2}\right)((1+k) n-(2-\beta)(1+\beta))$.

Then, $p^{B *}=\frac{L+M+N}{K}$.

From the above expressions, it can be checked that $q^{B *}>q^{C *}$ for all $n \in[0,1), k \in[0,1]$ and $\beta \in(0,1)$ such that $\beta<k n$.

$p^{B *}>p^{C *}$ when $\frac{1+\beta}{1+k}<n<1$.

Equilibrium profits are as follows.

$\pi^{B *}=\frac{(\alpha-c)^{2}\left(1-\beta^{2}\right) \lambda\left(\left(2-n-k n-\beta-\beta^{2}\right)^{2}((1+k) n-(2-\beta)(1+\beta))^{2} \lambda-2\left(1-\beta^{2}\right)\left(2-n-\beta^{2}\right)^{2}\right)}{\left(2\left(1-\beta^{2}\right)\left(2-n-\beta^{2}\right)-\left(2-n+k n-\beta-\beta^{2}\right)((1+k) n-(2-\beta)(1+\beta))^{2} \lambda\right)^{2}}$,

$\pi^{C *}=\frac{(\alpha-c)^{2} \lambda\left(-2(2-n)^{2}+(2-(1-k) n-\beta)^{2}(2-n-k n+\beta)^{2} \lambda\right)}{\left(-2(2-n)+(2-(1-k) n-\beta)(2+n+k n-\beta)^{2} \lambda\right)^{2}}$

It can be checked that $\pi^{B *}>\pi^{C *}$ for all $n \in[0,1), k \in[0,1]$ and $\beta \in(0,1)$ such that $\beta<k n$. 
(ii) When $\beta>k n$ and $k>\bar{k}$, we obtain the same expressions as in (i). It can be easily checked that $q^{B *}>q^{C *}$ and $p^{B *}<p^{C *}$ for all $n \in[0,1), k \in[0,1]$ and $\beta \in(0,1)$. [QED] 